\section{P145 MEDICAL CO-MORBIDITIES IN PATIENTS REFERRED FOR SPECIALIST ASSESSMENT OF INDUCIBLE LARYNGEAL OBSTRUCTION AND DYSFUNCTIONAL BREATHING}

1J Haines, ${ }^{1} \mathrm{R}$ Daly, ${ }^{2} \mathrm{SJ}$ Fowler. ${ }^{1}$ North West Lung Centre, University Hospital of South Manchester, Manchester, UK; ${ }^{2}$ Division of Infection, Immunity and Respiratory Medicine, University of Manchester, Manchester, UK

\subsection{6/thoraxjnl-2017-210983.287}

Introduction As part of our tertiary multi-disciplinary complex breathlessness service we run a weekly 'one-stop assessment day' for new referrals. Referral requests include assessment of refractory breathlessness felt due to inducible laryngeal obstruction (ILO) and/or dysfunctional breathing. Patients undergo clinical history and evaluation, spirometry, fractional exhaled nitric oxide (FENO), blood testing and laryngoscopy (with challenge if appropriate).

Aims To evaluate initial clinical plans of those attending onestop assessment days and understand the prevalence and type of medical comorbidities.

Methods Patient demographics and clinical data were retrospectively collated from clinical records of individuals who attended for assessment between November 2016 and June 2017.

Results Full assessments were available for 79 patients [72\% female; mean (SD) age 45.6 (13.6) years; FEV $_{1}(\mathrm{n}=40) 2.6$ (0.7) L; FVC $(n=40) 3.3$ (0.9) L; FENO $(n=33) 39.0(41.2)$ ppb; blood eosinophils $(n=68)$ median (range) $0.2(0.1-2.9)$ $\mathrm{x} 10^{9}$ cells $/ \mathrm{ml}$. Fifty two percent had endoscopically confirmed inspiratory ILO, and of these $15 \%$ had an associated dysfunctional breathing pattern. Initial clinic plans included instigation of medical treatment $(n=12)$, further investigations of untreated co-morbidities $(n=33)$, speech and language therapy treatment $(n=30)$, physiotherapy assessment and treatment $(n=9)$ and onward referral to non-respiratory specialists $(n=5)$. Of those requiring further investigation $73 \%$ were asthma related and $21 \%$ were for reflux. Medical treatments instigated were mainly related to asthma or bronchiectasis (92\%). Secondary analysis of those needing further investigation or medical treatment revealed $39 \%$ had inspiratory laryngeal obstruction, 13\% had exaggerated expiratory closure, and $23 \%$ had noted laryngeal hypersensitivity alone.

Conclusion There is a significant proportion of individuals who have untreated or under investigated co-morbidity (predominantly asthma) when referred for specialist complex breathlessness assessment. Those with untreated disease demonstrated abnormal responses in the upper airway and further support the relationship between ILO and asthma. Optimised medical intervention is important to ensure any aggravants of secondary diagnoses (e.g., ILO) are addressed adequately and their impact is minimised.

\section{P146 CAN MASKS PROTECT YOU FROM AIR POLLUTION?}

NM Liu, T Wan, EC Russell-Jones, J Grigg. Queen Mary University of London, London, UK

\subsection{6/thoraxjn-2017-210983.288}

Introduction Inhalation of diesel soot (black carbon) is associated with respiratory morbidity and mortality. Numerous facemasks that claim to reduce inhaled dose are available commercially, often aimed at the cycling community. To date it remains unclear whether these actually reduce exposure. In this study we sought to assess the effectiveness of some of masks available in the UK.

Methods We chose to assess 5 facemasks; i) Totobobo, ii) FFP3 industrial, iii) surgical, iv) Respro City Anti-Pollution, and v) Dettol Protect+. Masks was placed using an air tight seal at one end of a spacer chamber (Aerochamber). Researchers breathed through the spacer, and air within the spacer chamber sampled by an aethalometer (MicroAeth AE51) every $30 \mathrm{~s}$. For each $30 \mathrm{~s}$ period, spacer black carbon $\left(\mathrm{ng} / \mathrm{m}^{3}\right)$ was compared with ambient black carbon. Each mask was tested for at least $15 \mathrm{~min}$ on the pavement of busy roads in Marylebone and Whitechapel. Data are expressed as; i) mean of difference $( \pm$ SEM) between ambient and spacer air black carbon and ii) as percentage reduction of mean black carbon. Data are compared by paired T-test.

Results Totobobo mask was the most effective with a mean difference of $-2022 \mathrm{ng} / \mathrm{m}^{3} \quad\left( \pm 175 \mathrm{ng} / \mathrm{m}^{3}, \mathrm{p}<0.0001 ; 71 \%\right.$ reduction, figure 1). The FFP3 mask had a mean difference of $-1613 \mathrm{ng} / \mathrm{m}^{3} \quad\left( \pm 204 \mathrm{ng} / \mathrm{m}^{3}, \mathrm{p}<0.0001 ; 44.2 \%\right.$ reduction $)$; Dettol Protect + mask with the USB ventilator on had a mean difference of $-331.9 \mathrm{ng} / \mathrm{m}^{3}\left( \pm 74.89 \mathrm{ng} / \mathrm{m}^{3}, \mathrm{p}<0.0001 ; 42 \%\right.$ reduction). With the ventilator off, the Dettol Protect + had a mean difference of $-530 \mathrm{ng} / \mathrm{m}^{3}\left( \pm 147 \mathrm{ng} / \mathrm{m}^{3}, \mathrm{p}<0.01 ; 42 \%\right.$ reduction). The Repro City had a mean difference of -261 $\mathrm{ng} / \mathrm{m}^{3}$ ( $\pm 113 \mathrm{ng} / \mathrm{m}^{3}, \mathrm{p}<0.05 ; 30 \%$ reduction), and the surgical mask had a trend for increased spacer black carbon +2252 $\mathrm{ng} / \mathrm{m}^{3}\left( \pm 1071 \mathrm{ng} / \mathrm{m}^{3}, \mathrm{p}=0.05\right)$.

Conclusions Four of the five masks tested reduced spacer black carbon. The USB chargeable fan of the Dettol Protect + mask added minimal benefit. Why the surgical mask did not reduce black carbon is unclear but we speculate that condensation from exhalation impaired particle filtering.

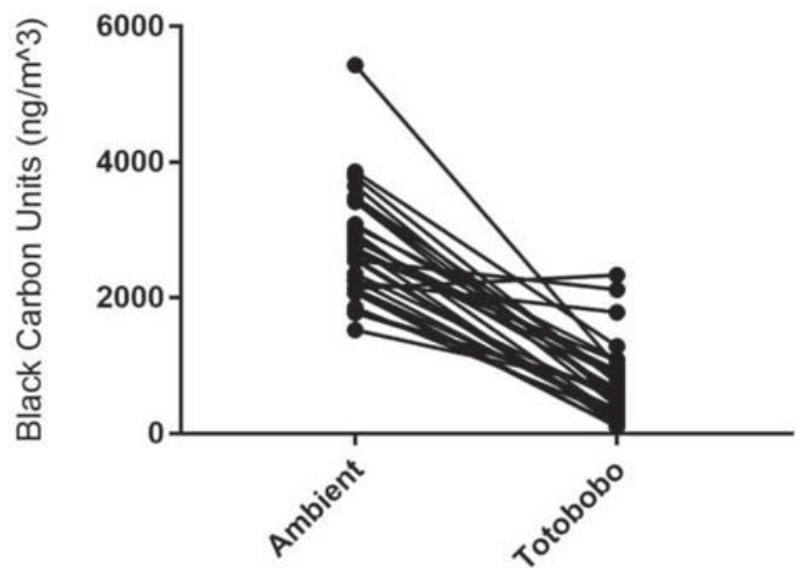

Abstract P146 Figure 1 Black carbon concentrations of ambient unfiltered air compared to air filtered by totobobo mask.

\section{A clinical update in interstitial lung disease}

\section{P147 THE CHANGING SHAPE OF PATIENTS WITH IDIOPATHIC PULMONARY FIBROSIS}

${ }^{1}$ RL Wollerton, ${ }^{1} \mathrm{CJ}$ Scotton, ${ }^{2} \mathrm{MA}$ Gibbons. ${ }^{1}$ University of Exeter, Exeter, UK; ${ }^{2}$ Royal Devon and Exeter Hospital, Exeter, UK

10.1136/thoraxjnl-2017-210983.289 